\title{
Interleukin-1 $\beta$ Inhibition Prevents Choroidal Neovascularization and Does Not Exacerbate Photoreceptor Degeneration
}

\author{
Sophie Lavalette, ${ }^{\star \dagger \ddagger}$ William Raoul, ${ }^{\text {†† }}$ \\ Marianne Houssier, ${ }^{, \dagger \ddagger}$ Serge Camelo, ${ }^{\star \dagger \ddagger}$ \\ Olivier Levy, ${ }^{\star \dagger \ddagger}$ Bertrand Calippe, ${ }^{* \dagger \ddagger}$ \\ Laurent Jonet, ${ }^{\star \dagger \ddagger}$ Francine Behar-Cohen, ${ }^{\star \star \neq \S}$ \\ Sylvain Chemtob, ${ }^{\text {III }}$ Xavier Guillonneau, ${ }^{,+\ddagger}$ \\ Christophe Combadière, ${ }^{* * \dagger}$ \\ and Florian Sennlaub* ${ }^{\star \uparrow \S}$
}

$\mathrm{Cx} 3 \mathrm{cr} \mathbf{1}^{-1-}$ mice. Our results suggest that IL-1 $\beta$ inhibition might represent a valuable and safe alternative to inhibition of vascular endothelial growth factor in the control of $\mathrm{CNV}$ in the context of concomitant photoreceptor degeneration as observed in age-related macular degeneration. (AmJ Pathol 2011, 178:2416-2423; DOI: 10.1016/j.ajpath.2011.01.013)

The IL-1 family of cytokines plays a key role in the initiation of acute inflammatory responses. ${ }^{1} \mathrm{IL}-1 \beta$ interacts with IL-1 receptor I (IL-1RI), composed of IL-1R and IL-1R accessory protein subunits. IL-1 receptor antagonist (IL$1 \mathrm{Ra}$ ) competes with IL-1 $\beta$ for its binding site. ${ }^{1} \mathrm{IL}-1 \beta$ is a potent inflammatory mediator with chemotactic ${ }^{2}$ and angiogenic ${ }^{3,4}$ properties. It is a neurotoxic mediator in ischemic brain injury ${ }^{5}$ but can attenuate glutamate neurotoxicity in the retina ${ }^{6}$ and protect against light-induced or hereditary photoreceptor degeneration. ${ }^{7,8}$

Age-related macular degeneration (AMD) is the leading cause of vision loss in elderly persons in industrialized countries. ${ }^{9}$ Its most prominent pathologic features are photoreceptor degeneration and choroidal neovascularization (CNV). ${ }^{10}$ In AMD, IL-1 $\beta$ is secreted by retinal pigment epithelium (RPE) cells and $\mathrm{CD} 8^{+}$cells in choroidal neovascular membranes ${ }^{11}$ and is therefore a possible pro-angiogenic and neuroprotective or neurotoxic mediator in AMD.

IL-1Ra is clinically used to treat juvenile idiopathic arthritis $^{12}$; it has been shown to inhibit neurotoxicity in ischemia in animal models. ${ }^{13}$ Intravitreal human IL-1Ra injections have been shown to efficiently inhibit CNV in

Supported by grants from INSERM, ANR "blanc" (AO5120DD), European Grant "Innochem" (LSHB-CT-2005-518167), ANR Maladies Neurologiques et Psychiatriques (ANR-08-MNPS-003) and ERC starting grant (ERC-2007 St.G. 210345). F.S. is a recipient of a contract "Interface" from Assistance Publique-Hopitaux de Paris.

S.L., W.R., M.H., and S.C. contributed equally to this work.

Accepted for publication January 13, 2011.

Address reprint requests to Florian Sennlaub, M.D., Ph.D., Centre de Recherche des Cordeliers, Equipe 21, 15, rue de l'école de Médecine, 75006 Paris, France. E-mail: Florian.Sennlaub@inserm.fr. 
a rat model. ${ }^{14}$ To analyze the possible implication of $\mathrm{IL}-1 \beta$ in CNV and retinal degeneration, we studied the expression of IL-1 $\beta$ in laser-induced CNV in mice and in light-induced retinal degeneration in rats and mice. We localized IL-1 $\beta$ expression by IHC and inhibited IL-1 $\beta$ activity with IL-1Ra supplementation.

\section{Materials and Methods}

\section{Animals}

Ten-week-old Wistar rats and C57B6j wild-type mice were purchased from the Janvier Breeding Center (Le GenestSt-Isle, France). Cx3 $\mathrm{Cr}^{-1-}$ C57B6j mice were backcrossed for six generations into the BALB/c background (Janvier Breeding Center) to obtain the $\mathrm{C}_{3} \mathrm{Cr}^{-1-}$ BALB/c strain and kept in specific pathogen-free conditions with food and water available ad libitum and housed in a 12/12 hours light/dark (100 to 500 lux) cycle. Animal experiments were approved by the Institutional Animal Care and Use Committee.

\section{Laser Coagulation}

Ten-week-old C57BL/6 mice were anesthetized with an intramuscular injection of ketamine $(50 \mathrm{mg} / \mathrm{kg})$ and xylazine $(10 \mathrm{mg} / \mathrm{kg})$. Their pupils were fully dilated with $1 \%$ tropicamide. Coverslips positioned on the mouse cornea were used as a contact glass. Four laser coagulations were performed four to five disk diameters away from the papillae with an Argon laser (532 nm) mounted on a slit lamp (400 mW, 50 milliseconds, and $50 \mu \mathrm{m}$ ). Mice were treated with daily subcutaneous injections of PBS or human recombinant IL-1Ra (Kineret; Biovitrum, Stockholm, Sweden) at $1 \mathrm{mg} / \mathrm{d} / \mathrm{kg}$ until sacrifice.

\section{Choroidal Flatmounts, IHC, and CNV Quantifications}

Eyes were enucleated, fixed in $4 \%$ paraformaldehyde for 15 minutes at room temperature and sectioned at the limbus; the cornea and lens were discarded (for CNV quantification, mice were perfused with fluorescein dextran $10^{6}$ before enucleation). Retinal and RPE/choroidal flatmounts were stained according to previously described standard immunohistochemical procedures. ${ }^{15}$ The primary antibodies and lectins used were Bandeirae simplicifolia lectin (Sigma-Aldrich, Saint Quentin Fallavier, France), goat anti-mouse IL-1 $\beta$ (R\&D Systems, Lille, France), rabbit polyclonal anti-IL-1RI (Santa Cruz Biotechnology Inc., Heidelberg, Germany), rabbit polyclonal anti-Iba1 (Wako, Neuss, Germany), rat anti-mouse Ly6G (Miltenyi Biotec, Paris, France), and goat anti-human Collagen IV (R\&D Systems). The corresponding Alexa secondary antibodies (Molecular Probes, Leiden, The Netherlands) were used to show the primary antibodies, and flatmounts were counterstained with DAPI. The choroids and retinas were radially incised, flatmounted, and viewed with the same fluorescence microscope. Flatmounts were viewed with a fluorescence microscope
(DM5500B; Leica, Nanterre, France). All immunostaining was repeated at least three times, and stains omitting the primary antibody served as negative controls. Ly6G-positive and Iba1-positive cells were counted on stained whole RPE/choroidal flatmounts up to the ciliary body and on the outer segment side of the retina. The surface covered by perfused CNV was measured on photographs of fluorescein dextran $10^{6}$ perfused choroidal flatmounts with ImageJ analysis software (surface covered by fluorescein staining). The average CNV size was calculated per eye.

\section{Microvascular Sprouting from Aortic Explants}

Aortae from adult C57BL/6 were cut into 1-mm-thick rings and covered with $30 \mu \mathrm{L}$ of Matrigel (BD Biosciences, Le Pont de Claix, France) in 24-well tissue cultures plates. Aortic rings were cultured for 3 days in Dulbecco's Modified Eagle's Medium (Invitrogen, Cergy Pontoise, France) containing $10 \%$ fetal calf serum, $1 \%$ penicillin/ streptomycin, and $0.2 \%$ fungizone. Explants were exposed to IL-1 $\beta$ ( $5 \mathrm{ng} / \mathrm{mL}$; R\&D Systems), IL-1Ra (10 mg/ $\mathrm{mL}$ ), and soluble vascular endothelial growth factor receptor 1 (VEGFR1s; $150 \mathrm{ng} / \mathrm{mL}$; R\&D Systems) from day 3 to day 7 of culture. Photographs of individual explants were taken every day, and the surface covered by the aortic ring and the vascular sprouts was measured daily from day 3 to day 7 . The surface of each individual aortic ring and pre-incubation sprouts at day 3 was subtracted from the surface at day 4 to calculate the vascular sprouting that occurred in the presence of the ligands and controls.

\section{Reverse Transcription and Real-Time PCR}

Total RNA was isolated with NucleoSpin RNA II Kit (Macherey-Nagel, Hoerdt, France). Single-stranded cDNA was synthesized from total RNA (pretreated with DNasel amplification grade) with the use of oligo(dT) as primer and superscript reverse transcriptase (Invitrogen, Cergy Pontoise, France). Subsequent real-time PCR was performed with the use of cDNA, qPCR SuperMix-UDG Platinum SYBR Green (Invitrogen), and the following primers (0.5 $\mathrm{pmol} / \mu \mathrm{L}$ ): $\mathrm{mm}$ (mouse) actin sense: 5'-AAGGCCAACCGTGAAAAGAT-3'; mm actin antisense: 5'-GTG GTACGACCAGAGGCATAC- $3^{\prime} ; \mathrm{mm} \quad \mathrm{LL}-1 \beta$ sense: 5'-CATGGAATCCGTGTCTTCCT-3'; $\mathrm{mm} \quad \mathrm{IL}-1 \beta$ antisense: 5'-GAGCTGTCTGCTCATTCACG-3'; mm VEGF sense: 5'-GTGAGCCAGGCTGCAGGAAG-3'; mm VEGF antisense: 5'-GAATGCGTCTGCCGGAGTCT-3'; rn (rat) actin sense: 5'-AAAGAAAGGGTGTAAAACGCAG-3'; rn actin antisense: 5'-AAAGACCTCTATGCCAACACAG-3'; rn IL-1 $\beta$ sense: $5^{\prime}$-GGAACCCGTGTCTTCCTAAA- $3^{\prime}$; and rn IL-1 $\beta$ antisense: 5'-CTGACTTGGCAGAGGACAAA-3' .

PCR reactions were performed in 40 cycles of 15 seconds at $95^{\circ} \mathrm{C}, 45$ seconds at $60^{\circ} \mathrm{C}$. Product was not generated in control reactions in which reverse transcriptase was omitted during cDNA synthesis. 


\section{Light-Induced Degeneration}

Ten-week-old rats and 8-week-old $\mathrm{C} \times 3 \mathrm{Cr}^{-1-}$ mice were adapted to darkness for 12 hours, and pupils were fully dilated with $1 \%$ atropin (Novartis, Rueil Malmaison, France). Animals were then exposed to green LED light (4500 lux) for 12 hours and subsequently kept in cyclic 12 hours/12 hours normal animal facility conditions. Control and light-exposed rats and mice were treated with daily subcutaneous injections of PBS or IL-1Ra (Kineret; Biovitrum) at $1 \mathrm{mg} / \mathrm{d} / \mathrm{kg}$ until sacrifice and a volume of $5 \mu \mathrm{L}$ (rats) or $2 \mu \mathrm{L}$ (mice) of IL-1Ra at $150 \mathrm{mg} / \mathrm{mL}$ was injected intravitreally at day 0 and day 3 after illumination.

\section{Protein Analysis}

Eyes were enucleated and sectioned at the limbus, and the cornea and lens were discarded. The complex retina/RPE/choroid/sclera was placed in $150 \mu \mathrm{L}$ of PBS $1 \times$ supplemented with a protease inhibitor cocktail (Calbiochem, Fontenay-sous-Bois, France) followed by homogenization with a plastic pestle. The lysate were cleared of debris by centrifugation at 2000 rcf for 10 minutes at $4^{\circ} \mathrm{C}$. Total protein content of supernatant was determined by commercial assay (Bradford kit, Eragnysur-Oise, France). Supernatant IL-1 $\beta$ level was determined with a sandwich enzyme-linked immunoabsorbent assay, according to the manufacturer's instructions (R\&D Systems) and normalized for total protein.

\section{Histology}

For histology, eyes were fixed in $0.5 \%$ glutaraldehyde, 4\% paraformaldehyde PBS for 2 hours, dehydrated, and mounted in HistoResin. Oriented sections (5 $\mu \mathrm{m})$, crossing the center of the laser injury (CNV model) or inferior pole, optic nerve, and superior pole (light-induced model), were cut and stained with toluidine blue. Rows of nuclei in the outer nuclear layer were counted at different distances from the injury site (CNV model) or optic nerve (light-induced model).

\section{Statistical Analysis}

GraphPad Prism 5 (GraphPad Software Inc., San Diego, CA) was used for data analysis and graphic representation. All values are reported as mean \pm SEM. Statistical analysis was performed by one-way and two-way analysis of variance followed by post hoc Bonferroni's test for comparison among means. $P<0.05$ was considered statistically significant.

\section{Results}

\section{IL-1 $\beta$ Is Induced in Laser-Induced}

Neovascularization and Localizes to the Injury Site

$\mathrm{IL}-1 \beta$ is known for its pro-angiogenic properties. ${ }^{3,4}$ It is secreted by $\mathrm{CD}^{+} 8^{+}$cells in choroidal neovascular mem-
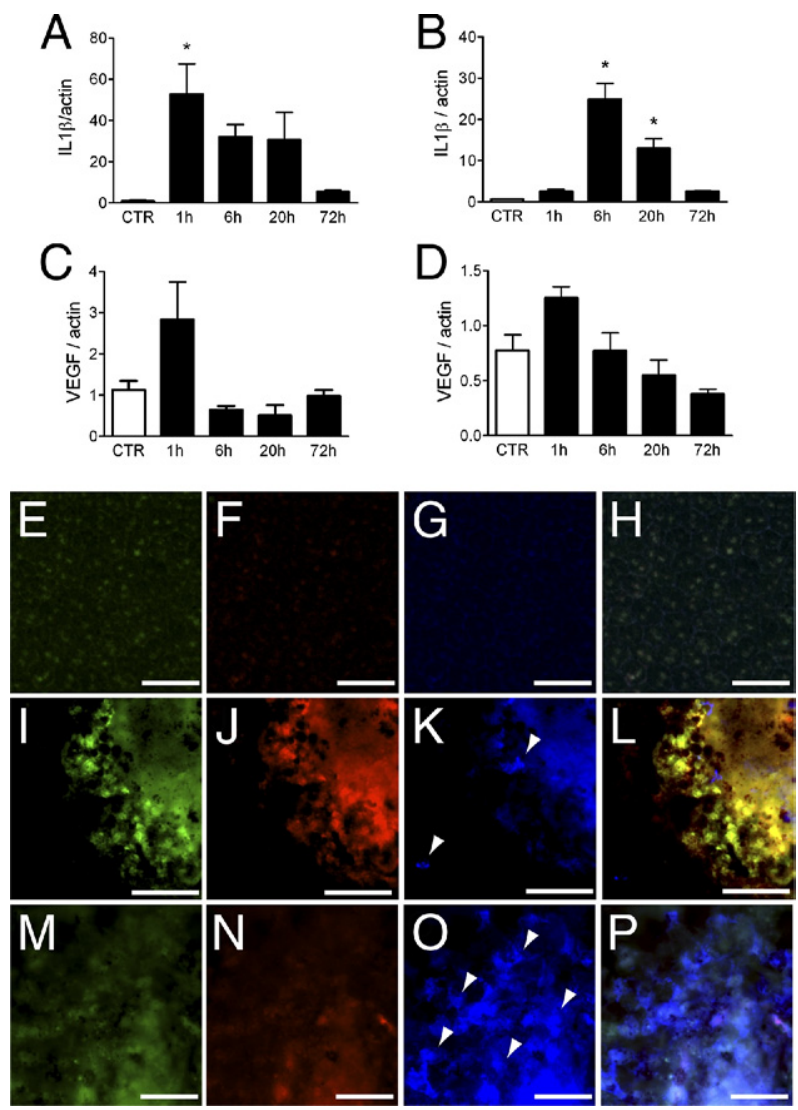

Figure 1. IL-1 $\beta$ expression in laser-induced neovascularization. IL-1 $\beta$ realtime PCR in retina $(\mathbf{A})$ and choroid $(\mathbf{B})$ and VEGF real-time PCR in retina $(\mathbf{C})$ and choroid (D) at different time points in laser-induced CNV in the eye cup of C57BL/ 6 mice (control $n=4$ eyes, 1 hour $n=8$ eyes, 6 hours $n=7$ eyes, 20 hours $n=5$ eyes, 72 hours $n=4$ eyes; one-way analysis of variance ${ }^{*} P$ $=0.03(\mathbf{A}$ and $\mathbf{B})$. Representative micrographs of IHC of uninjured $(\mathbf{E}-\mathbf{H}), 10$ hours (I-L), and 72 hours (M-P) of laser-injured choroid/RPE flatmounts ( $n$ $=4$ mice per time point). IL- $1 \beta$ staining (green staining $\mathbf{E}, \mathbf{I}$, and $\mathbf{M}$ ), Ly $6 \mathrm{C}$ staining (red staining $\mathbf{F}, \mathbf{J}$, and $\mathbf{N}$ ), Iba1 staining (blue staining $\mathbf{G}, \mathbf{K}$, and $\mathbf{O}$ ) merged photographs $(\mathbf{H}, \mathbf{L}$, and $\mathbf{P})$. Scale bars $=50 \mu \mathrm{m}(\mathbf{E}-\mathbf{P})$. Arrowheads: Iba1-positive cells ( $\mathbf{K}$ and $\mathbf{O}$ ).

branes in AMD. ${ }^{11}$ Its inhibition has been shown to prevent laser-induced subretinal neovascularization in rats, but its induction, expression pattern, and effect on inflammation in the laser model has not been analyzed. ${ }^{14,16} \mathrm{We}$ first analyzed IL-1 $\beta$ expression at different time points in laser-induced CNV in the retina (Figure $1 \mathrm{~A}$ ) and choroid (Figure 1B) of C57BL/6 mice. A strong induction of IL-1 $\beta$ mRNA is observed as early as 1 hour in the retina (55fold) and at 6 hours (35-fold) and 20 hours (18-fold) in the choroid. To a lesser extent, a tendency for vascular endothelial growth factor (VEGF) mRNA induction was detected in the retina at 1 hour (Figure $1 \mathrm{C}$ ) but not in the choroid (Figure 1D; control, $n=4 ; 1$ hour, $n=8 ; 6$ hours, $n=7 ; 20$ hours, $n=5$; 72 hours, $n=4$ retinas/choroids). To identify IL-1 $\beta$-expressing cells, we performed IHC of $\mathrm{IL}-1 \beta$ (green staining; Figure $1, \mathrm{E}, \mathrm{I}$, and $\mathrm{M}$ ), the neutrophil marker Ly6G (Figure 1, F, J, and N), and the monocyte/macrophage marker Iba1 (Figure 1, G, K, and O) on choroidal/RPE flatmounts of uninjured control eyes (Figure $1, \mathrm{E}-\mathrm{H}$ ) and 10 hours (Figure 1, I-L) and 72 hours (Figure 1, M-P) after laser impact. Uninjured control eyes did not stain positive for IL-1 $\beta$, Ly6G, or Iba1 (Figure 1, 

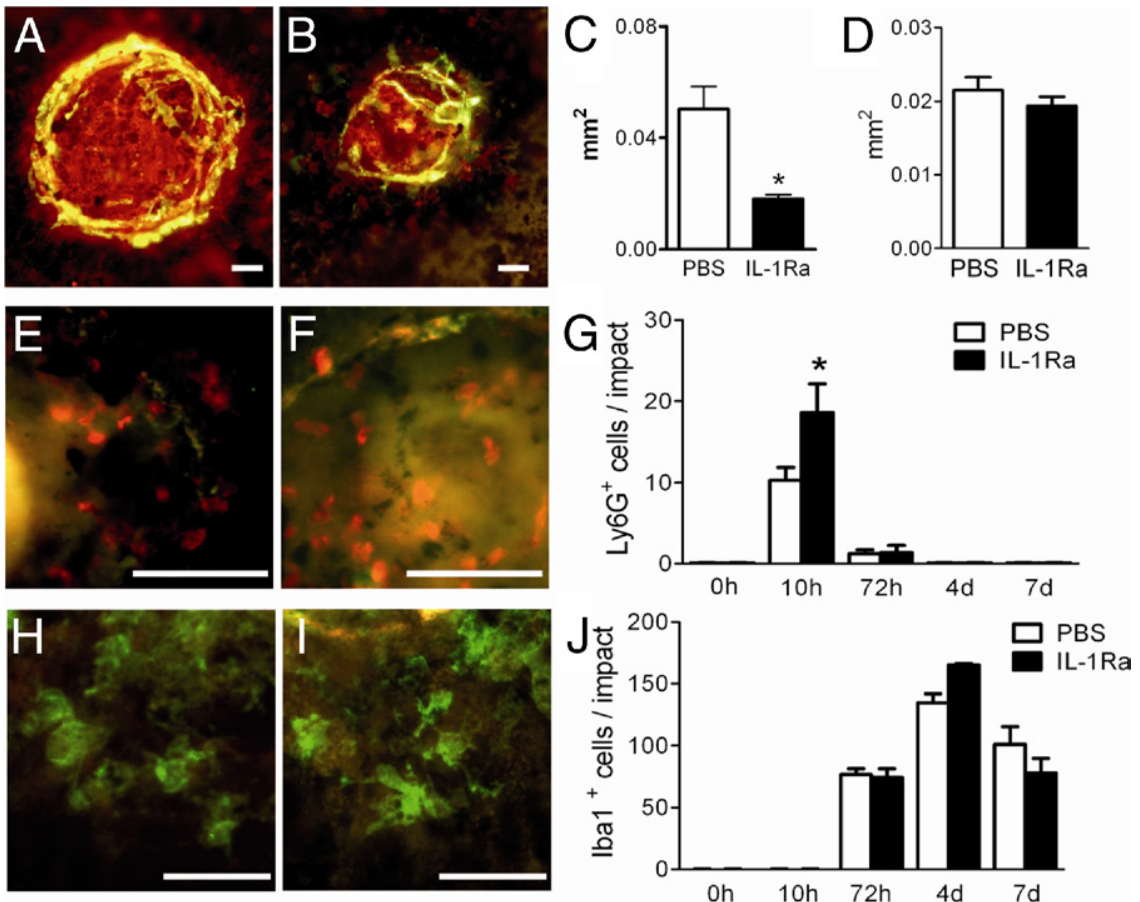

Figure 2. IL-1Ra inhibits $\mathrm{CNV}$ independently of macrophage recruitment. Photographs of isolectin (red) stained and fluorescein dextran perfused (green) RPE/choroidal flatmounts of PBStreated $(\mathbf{A} ; n=4)$ and IL-1Ra-treated $(\mathbf{B} ; n=5)$ C57BL/6 mice 14 days after laser injury. Quantification of fluorescein-positive area $(\mathbf{C}$; MannWhitney $\left.{ }^{*} P<0.0001\right)$. Quantification of RPE lesion size of PBS- ( $n=4$ mice) and IL-1Ra$(n=4$ mice) treated mice at 10 hours after laser impact (D). Representative photographs of Ly6G- (red) and Iba1- (green) stained RPE/choroidal flatmounts of the border of the injured area of saline- (E and $\mathbf{H} ; n=3$ mice/group) and IL-1Ra-treated (F and $\mathbf{I} ; n=3$ mice/group) mice 10 hours $(\mathbf{E}$ and $\mathbf{F})$ and 72 hours $(\mathbf{H}$ and $\mathbf{I})$ after laser injury. Quantification of Ly6G- (G) and Iba1- (J) positive cells/impact at different time points (F; Mann-Whitney $\left.{ }^{*} P=0.14\right)$. Scale bars $=50 \mu \mathrm{m}(\mathbf{A}, \mathbf{B}, \mathbf{E}, \mathbf{F}, \mathbf{H}$, and $\mathbf{I})$.
$\mathrm{E}-\mathrm{H})$. At 10 hours after the injury small IL-1 $\beta$-positive cells are visible at the site of effect (Figure 1I) $(n=4$ eyes). Triple labeling at 10 hours with the use of the neutrophil marker Ly6G (red fluorescence; Figure 1J) and the monocyte/macrophage marker lba1 (blue fluorescence; Figure $1 \mathrm{~K}$ ) shows that the IL- $1 \beta$-positive cells are Ly6G positive and Iba1 negative (Figure $1 \mathrm{~L}$ merge). Most of the detected IL-1 $\beta$-positive cells were Ly6G positive. Seventy-two hours after the impact IL-1 $\beta$ (Figure $1 \mathrm{M}$ ) and Ly6G (Figure $1 \mathrm{~N}$ ) were faint and diffuse, whereas numerous Iba1-positive cells were detected at the injury site (blue staining; Figure 1, $O$ and $P$ merge). IHC at 10 hours and 72 hours, omitting the primary antibodies, resulted in no staining (data not shown) ( $n=4$ eyes per time point).

\section{IL-1Ra Inhibits CNV Independently of Macrophage Recruitment}

To evaluate the effect of $\mathrm{IL}-1 \beta$ induction on CNV we treated one group of experimental animals with subcutaneous saline injections ( $n=4$ mice) and one group with subcutaneous injections of $1 \mathrm{mg} / \mathrm{kg} /$ day recombinant human IL-1Ra ( $n=5$ mice). At day 14 after laser injury the CNV was visualized on isolectin-stained (red staining), fluorescein dextran perfused (green/yellow staining) RPE/choroidal flatmounts of saline- (Figure 2A) and IL1Ra-treated mice (Figure 2B). Mature, perfused CNV (presenting a tubular structure with a lumen) was quantified as fluorescein-positive surface (Figure 2C). IL-1Ratreated animals showed a $60 \%$ reduction in CNV. Initial lesion size at 10 hours after laser impact, identified by the loss of the RPE cell layer, was quantified on choroidal/ RPE flatmounts of saline- and IL-1Ra-treated mice and showed no significant difference (Figure 2D), excluding a possible initial difference of the laser injury in the two groups.

IL-1 $\beta$ has chemotactic properties and can alter macrophage recruitment to the granulomateous tissue that forms after injury. ${ }^{2}$ It might thereby indirectly influence angiogenesis. To test this hypothesis, we visualized neutrophils and macrophages/microglial cells 10 hours (Figure 2, E and F) and 72 hours (Figure 2, $\mathrm{H}$ and I) after laser injury, on Ly6G (red staining) and Iba1 (green staining) stained RPE/choroidal flatmounts of saline- (Figure 2, E and $\mathrm{H} ; n=3$ mice) and IL-1Ra-treated (Figure 2, $\mathrm{F}$ and I; $n=3$ mice) mice. Neutrophil (Figure 2G) and macrophage/microglial cell (Figure 2J) prevalence were quantified. Ly6G-positive neutrophils were significantly recruited to the injury site, reaching their maximum at 10 hours. Neutrophil recruitment was stronger in IL-1Ratreated animals (Figure 2G; $n=3$ to 4 mice per time point). IL-1Ra treatment did not alter Iba1-positive macrophage/microglial cell recruitment, which reached the maximum in both saline- and IL-1Ra-treated groups at 4 days (Figure 2J).

\section{IL-1 $\beta$ Induces Vascular Sprouting in Aortic Rings}

$\mathrm{IL}-1 \beta$ exerts its activity by acting on the IL-1RI. ${ }^{1}$ It induces angiogenesis in the cornea in vivo, ${ }^{3}$ IL-6 expression, ${ }^{17}$ and microparticle release from vascular endothelial cells in vitro. ${ }^{18} \mathrm{IL}-1 \mathrm{RI}$ is expressed on numerous cell types; notably, it is constitutively expressed on vascular endothelium. ${ }^{17} \mathrm{IL}-1 \mathrm{RI} \quad \mathrm{HC}$ on choroidal/RPE flatmounts of C57BL/6 mice 5 days after the injury shows IL-1RI-positive staining around the lesion site (Figure $3 A$ ) ( $n=3$ mice). Double labeling with the use of the vascular endothelial cell marker collagen IV (red fluorescence; Figure 3B) shows that IL-1RI is expressed in the vascular endothe- 

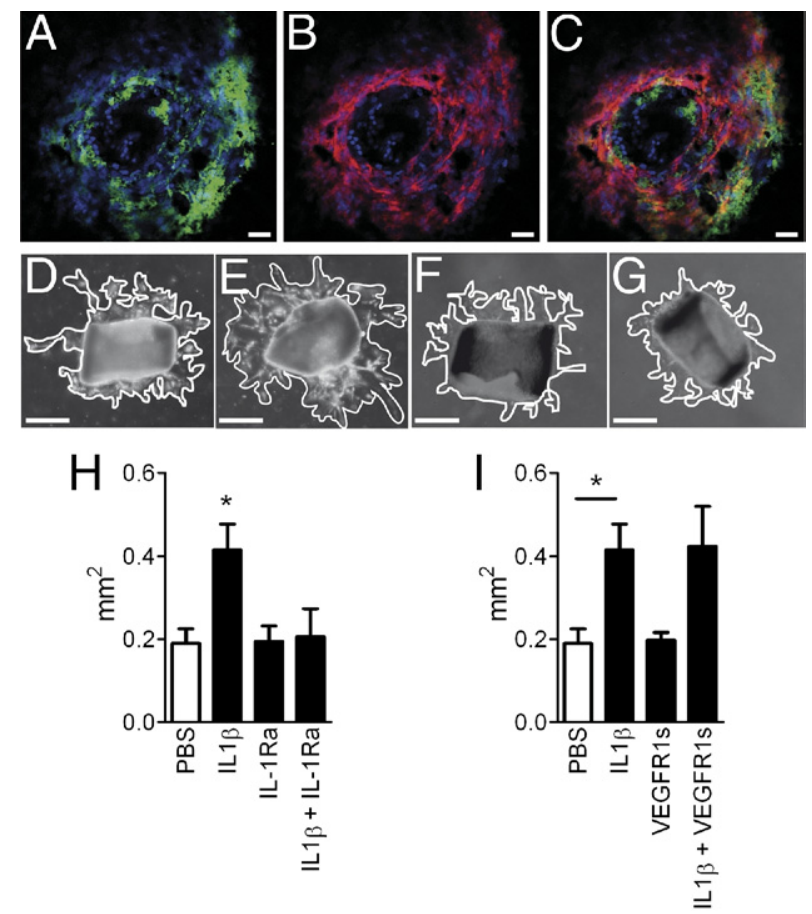

Figure 3. IL-1 $\beta$ induces vascular sprouting in aortic rings. Confocal microscopic image of IL-1RI (green staining A) and Collagen IV IHC (red staining $\mathbf{B}$, merge $\mathbf{C})$ of the laser-injury site at day $5(n=3$ mice $)$ of $\mathrm{C} 57 \mathrm{BL} / 6$ mice. Photographs of aortic rings at day 4, 24 hours after incubation with control (D), IL-1 $\beta$ (E), IL-1Ra (F), or IL-1 $\beta$ and IL-1Ra (G). H: Measurements of the area of vascular sprouting in the presence of control $(n=6)$, IL-1 $\beta(n=$ $12)$, IL-1Ra $(n=6)$, or IL-1 $\beta$ and IL-1Ra $(n=6)$. I: Measurements of the area of vascular sprouting in the presence of control $(n=6)$, IL- $1 \beta$ ( $n=$ $12)$, soluble VEGFR1 $(n=5)$ or IL- $1 \beta$ and soluble VEGFR1 $(n=6)$. ${ }^{*} P<$ 0.05 one-way analysis of variance. Scale bars: $(\mathbf{A}-\mathbf{C})=50 \mu \mathrm{m} ;(\mathbf{D}-\mathbf{G})=$ $350 \mu \mathrm{m}$.

lium surrounding the lesion and in some unidentified cells (Figure 3C merge).

To test the effect of $\mathrm{IL}-1 \beta$ on vascular sprouting we used the aortic ring assay. Photographs at 4 days and 24 hours after ligand incubation show the vascular sprouting of PBS (Figure 3D), IL-1 $\beta$ (Figure 3E), IL-1Ra (Figure 3F), or IL-1 $\beta$ and $\mathrm{IL}-1 \mathrm{Ra}$ incubated aortic rings (Figure $3 \mathrm{G}$ ). Measurements of the area covered by the vascular sprouts showed a significant increase of growth in IL-1 $\beta$ exposed aortic rings after 24 hours of IL-1 $\beta$ exposure at 4 days that was inhibited by simultaneous IL-1Ra incubation (Figure $3 \mathrm{H}$ ). Vascular sprouting remained significantly increased up to 6 days (72 hours of ligand exposure) before aortic rings started dying (data not shown). Simultaneous incubation of $\mathrm{IL}-1 \beta$ with the soluble VEGFR1 did not significantly inhibit the effect of IL-1 $\beta$ incubation alone (Figure 3l).

\section{IL-1Ra Does Not Affect Photoreceptor Survival of Laser- and Light-Induced Injury}

In AMD, CNV develops in the context of photoreceptor degeneration. IL-1 $\beta$ supplementation has been shown to inhibit photoreceptor degeneration in rat models of lightinduced degeneration ${ }^{7}$ and to protect photoreceptor degeneration observed in Royal College of Surgeons rats. ${ }^{8}$ IL-1 $\beta$ inhibition might have a deleterious effect on retinal degeneration. Laser injury used to induce CNV also induces a local inflammatory reaction and retinal degeneration in the vicinity of the laser impact. To evaluate whether IL-1Ra influences the laser-induced photoreceptor degeneration, we treated laser-injured C57BL/6 mice with daily subcutaneous injections of saline ( $n=3$ mice) or IL-1Ra ( $n=4$ mice) and prepared histologic sections crossing the lesion site at day 14 (Figure 4, A and B, respectively). Quantification of rows of nuclei at increasing distances from the injury site showed no difference in photoreceptor cell loss in the vicinity of the laser impact (Figure 4C).

To analyze the effect of IL- $1 \beta$ inhibition in a non-neovascular context, we exposed Wistar rats to light-induced retinal degeneration and analyzed IL-1 $\beta$ expression by real-time PCR in eye cups (Figure 4D; control, $n=4$ eyes; 1 hour, $n=5$ eyes; 12 hours, $n=5$ eyes). IL- $1 \beta$ transcript was significantly induced (five times) in the eye at 12 hours after the onset of light-induced stress. To evaluate the influence of the endogenously produced $\mathrm{IL}-1 \beta$ on photoreceptor survival we injected Wistar rats with either PBS ( $n=4$ rats) or IL-1Ra ( $n=6$ rats) (subcutaneously 1 $\mathrm{mg} / \mathrm{kg} /$ day and intravitrealy and $5 \mu \mathrm{L}$ of a $150 \mathrm{mg} / \mathrm{mL}$
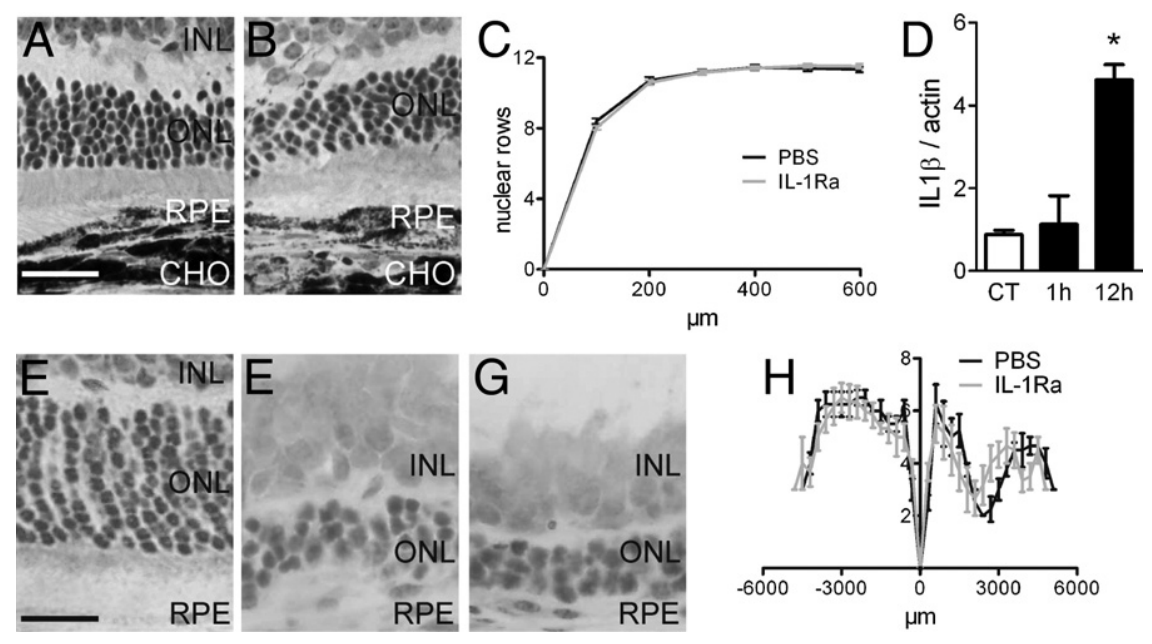

Figure 4. IL-1 and light- and laser-induced in jury. Histology of the photoreceptor cell layer at $100 \mu \mathrm{m}$ of the laser injury in PBS- $(\mathbf{A} ; n=3$ mice) and IL-1R- (B; $n=4$ mice) treated C57BL/6 mice. Quantification of number of rows of photoreceptor nuclei at increasing distance from the injury site in PBS- and IL-1Ra-treated animals (C). Real-time PCR of IL- $1 \beta$ expression in Wistar eye cup mRNA extracts $(\mathbf{D}$; control $n=$ 4, 1 hour $n=5,12$ hours $n=5$ ). Normal light-raised Wistar rats (E); light-injured PBStreated $(\mathbf{F} ; n=4)$ and light-injured IL-1Ratreated $(\mathbf{G} ; n=6)$ eyes. Quantification of number of rows of photoreceptor nuclei at different distances from the optic nerve measured on oriented sections, crossing the inferior pole, optic nerve, and superior pole $(\mathbf{H}) .{ }^{*} P=0.0003$. Scale bars: $\mathbf{A}$ and $\mathbf{B}=50 \mu \mathrm{m} ; \mathbf{E}-\mathbf{G}=20 \mu \mathrm{m}$. ONL, outer nuclear layer; INL, inner nuclear layer; $\mathrm{RPE}$, retinal pigment epithelium; $\mathrm{CHO}$, choroid; CT, control. 
solution at day 1 and day 3 to ensure penetration of a possibly intact blood retinal barrier in the eye). Control animals that were raised under normal light conditions showed no signs of toxicity at this dosage (data not shown). At 7 days, histology of rats treated with control (Figure 4E), with light-exposed PBS (Figure 4F), and lightexposed IL-1Ra (Figure 4G) showed significant thinning of the outer nuclear layer in both groups. Quantification of rows of nuclei at different distances from the optic nerve measured from the inferior pole to the superior pole showed no differences in photoreceptor cell loss throughout the retina (Figure $4 \mathrm{H}$ ).

\section{IL-1Ra Does Not Affect Photoreceptor Survival in Degeneration-Prone $\mathrm{C} \times 3 \mathrm{Cr}^{-/-}$Mice}

We have previously shown, that the T280M polymorphism of CX3CR1 leads to dysfunctional CX3CR1 and is associated with AMD. Furthermore, $C \times 3 \mathrm{Cr}^{-1-}$ mice develop spontaneous photoreceptor degeneration by the age of 18 months and exaggerated photoreceptor degeneration in light-induced models. ${ }^{19,20}$ Here, we analyzed the expression and effect of $\mathrm{IL}-1 \beta$ in the $C \times 3 \mathrm{Cr}^{-1-}$ model of AMD. First, we analyzed IL-1 $\beta$ expression in C57BL/6 $\mathrm{C} \times 3 \mathrm{Cr}^{+/+}$and $\mathrm{C} 57 \mathrm{BL} / 6 \mathrm{C} \times 3 \mathrm{Cr}^{-1-}$ mice at 3 and 18 months of age (Figure $5 \mathrm{~A} ; n=4$ eyes/group). IL-1 $\beta$ protein was significantly increased in 18-month-old C57BL/6 $\mathrm{C} \times 3 \mathrm{Cr}^{-1-}$ mice compared with $\mathrm{C} \times 3 \mathrm{Cr} 1^{+/+}$ mice. Similarly, 4500 lux light-exposed BALB $\mathrm{C} \times 3 \mathrm{Cr}^{+/+}$ and BALB $C \times 3 \mathrm{Cr}^{-1-}$ animals showed a significant increase of IL- $1 \beta$ protein 24 hours after onset of the light injury compared with normal light-raised $\mathrm{C}_{3} \mathrm{Cr}^{+/+}$and Cx3Cr1 ${ }^{-1-}$ mice (Figure 5B; $n=4$ eyes/group). Interestingly, the basal level of IL-1 $\beta$ expression was more important in young C57BL/6 mice than in BALB mice. The increase of IL-1 $\beta$ protein levels in light-induced injury in BALB Cx3Cr1 ${ }^{+/+}$and $\mathrm{C} \times 3 \mathrm{Cr}^{-1-}$ mice was not different from each other and comparable to 18-month-old C57BL/6 Cx3Cr1 $1^{-1-}$ mice. To evaluate if IL-1 $\beta$ plays a role in photoreceptor degeneration in the context of CX3CR1 deficiency, we exposed 2-month-old BALB Cx3Cr1 ${ }^{-1-}$ mice before significant spontaneous degeneration was observed to light-induced degeneration ${ }^{19}$ (Figure 5C). PBS ( $n=4$ mice) or IL-1Ra ( $n=6$ mice) were injected subcutaneously at $1 \mathrm{mg} / \mathrm{kg} / \mathrm{d}$ and intravitrealy ( $2 \mu \mathrm{L}$ of a $150-\mathrm{mg} / \mathrm{mL}$ solution) at day 1 and day 3 to ensure penetration of a possibly intact blood retinal barrier in the eye. Saline-treated controls ( $n=6$ mice; Figure 5D) degenerated similarly to $\mathrm{IL}-1$ Ra-treated $\mathrm{C} \times 3 \mathrm{Cr}^{-1-}$ mice (Figure 5E; $n=6$ mice), and no significant difference could be observed throughout the retina (Figure 5F). Control $\mathrm{C} \times 3 \mathrm{Cr}^{-1-}$ animals that were raised under normal light conditions and treated with intravitreal and subcutaneous PBS or IL-1Ra showed no signs of toxicity at this dosage (Figure 5G).

\section{Discussion}

We demonstrate that IL-1 $\beta$ expression rapidly increases in laser- and light-induced injury. The expression in laser-
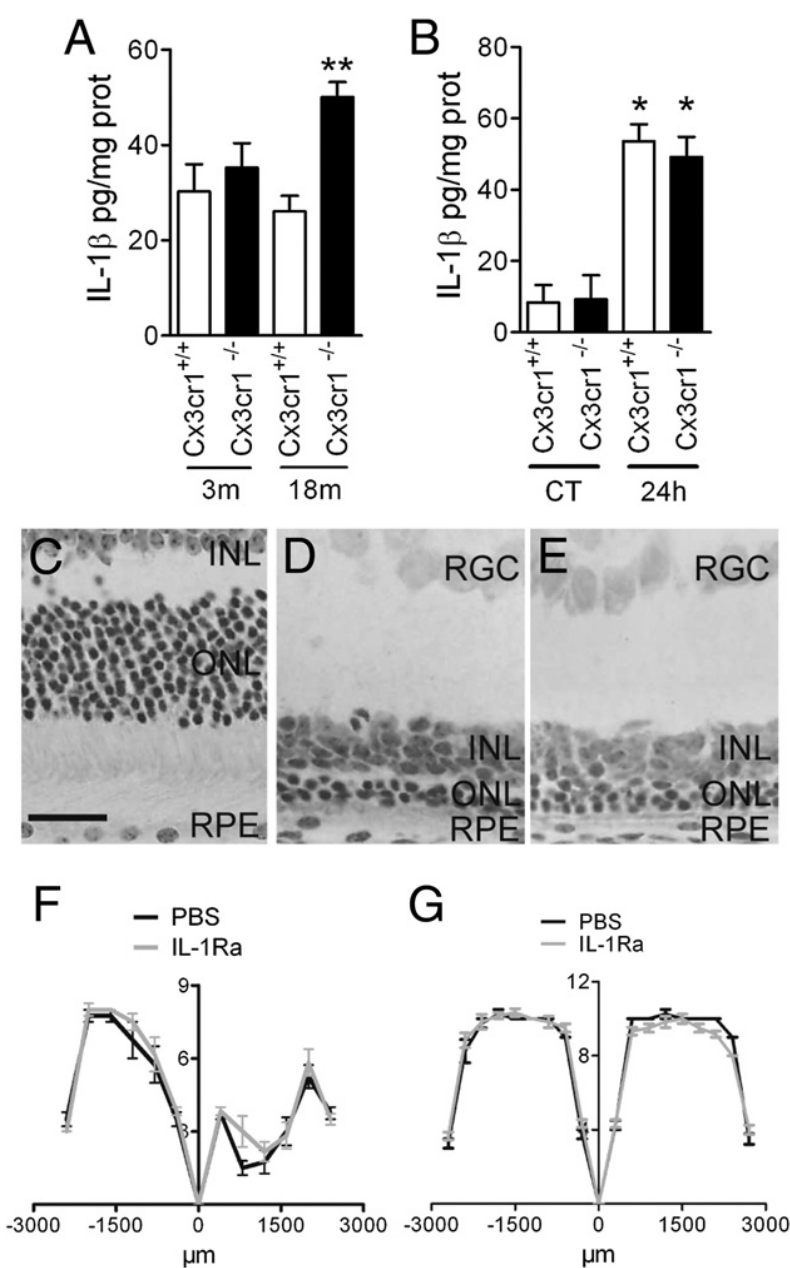

Figure 5. IL-1 $\beta$ and $C x 3 c r 1^{-/-}$AMD model and light-induced injury $\mathrm{C} \times 3 \mathrm{Cr}^{-1-}$ mice. IL-1 $\beta$ enzyme-linked immunoabsorbent assay of eye cups of 3- and 18-month-old C57BL/6 Cx3 $\mathrm{crl}^{+/+}$and $\mathrm{C} 57 \mathrm{BL} / 6 \mathrm{Cx} 3 \mathrm{cr} 1^{-/-}$animals (A; $n=5$ to 6 ). IL- $1 \beta$ enzyme-linked immunoabsorbent assay of eye cups of control and light-exposed 8-week-old BALB $\mathrm{Cx} 3 \mathrm{Cr}^{+/+}$(wild-type) and BALB $\mathrm{C} \times 3 \mathrm{Cr}^{-1-}$ eye cups (B; $n=4$ eyes per group). Normal lightraised BALB C $x 3 \mathrm{Cr}^{-/-}(\mathbf{C})$; light-injured PBS-treated BALB C $x 3 \mathrm{Cr}^{-1-}$ (D $n=4)$, and light-injured IL-1Ra-treated BALB $C x 3 c r 1^{-1-}(\mathbf{E} ; n=6)$ eyes. Quantification of number of rows of photoreceptor nuclei at different distances from the optic nerve on oriented sections of PBS- and IL-treated light-injured 2-month-old BALB $\mathrm{C} \times 3 \mathrm{crl}^{-1-}$ mice (F). Quantification of number of rows of photoreceptor nuclei at different distances from the optic nerve on oriented sections of PBS- and IL-1Ra-treated control BALB $\mathrm{C} \times 3 \mathrm{cr}^{-1-}$ mice $(\mathbf{G}) .{ }^{*} P<0.001 ;{ }^{* *} P=0.0055$. Scale bar $=25 \mu \mathrm{m}$. CT, control; ONL, outer nuclear layer; INL, inner nuclear layer; RPE, retinal pigment epithelium; RGC, retinal ganglion cells.

induced injury shows rapid induction that lasts for approximately 2 days (Figure 1). IHC at 10 hours localizes IL- $1 \beta$ mainly to infiltrating neutrophils, as shown by a positive Ly6G co-staining (specific for neutrophils and not expressed on monocytes ${ }^{21}$ ) and negative Iba1 costaining (specifically expressed on macrophages and microglial cells ${ }^{22}$ ) (Figure 1). The identity of IL-1 $\beta$-expressing cells was further confirmed by their multilobulated nuclei (data not shown) and is corroborated by the IL-1 $\beta$ expression kinetics that coincide with early neutrophil recruitment in CNV. ${ }^{23}$ Most IL-1 $\beta$-expressing cells in our experiments were Ly6G-positive neutrophils, and the contribution of Iba1-positive macrophages/microglia was negligible. Nevertheless, occasional IL-1 $\beta$ staining was 
also detected in RPE cells adjacent to the laser injury. Activated polymorphonuclear neutrophils have been shown to express $\mathrm{IL}-1 \beta,{ }^{24}$ and our data show that these cells are the predominant source of $\mathrm{IL}-1 \beta$ after laser injury in the mouse. $\mathrm{IL}-1 \beta$ is expressed in $\mathrm{CD}^{+} 8^{+}$cells in human neovascular membranes that were interpreted to be macrophages. ${ }^{11}$ Although macrophages can express CD68, it has been shown that the main CD68-expressing cells in the injured central nervous system are neutrophils. ${ }^{25}$ It is possible that neutrophils participate in IL-1 $\beta$ in AMD. Studies that use more specific markers of neutrophils and macrophages are needed to determine the cell types expressing IL-1 $\beta$ in the human disease.

$\mathrm{IL}-1 \beta$ inhibition by recombinant IL-1Ra significantly reduced the development of subretinal neovascularization in the mouse model of laser-induced subretinal neovascularization (Figure 2). Our results corroborate an earlier report that $\mathrm{IL}-1 \mathrm{Ra}$ inhibits neovascularization in a rat model. ${ }^{14,16}$

Neutrophils and macrophages promote CNV 23,26-28; $\mathrm{IL}-1 \mathrm{Ra}$ has been shown to inhibit macrophage recruitment to the atherosclerotic plaque in a mouse model. ${ }^{2}$ We therefore tested the influence of IL-1Ra treatment on neutrophil and macrophage recruitment to the laser-injury site as a possible mechanism of CNV inhibition (Figure 2). Interestingly, IL-1Ra treatment significantly increased the number of Ly6G-positive neutrophils at 10 hours, suggesting a possible IL- $1 \beta$-dependent negative feedback in neutrophil recruitment. No inhibition of macrophage/microglial cell recruitment was observed in IL1Ra-treated mice after laser injury. Therefore, IL-1Radependent inhibition of CNV is unlikely to be mediated by an inhibitory effect on the macrophage recruitment.

$\mathrm{IL}-1 \beta$ exerts its activity by acting on the IL-1RI. ${ }^{1}$ Vascular endothelium, which constitutively expresses IL$1 \mathrm{RI},{ }^{17}$ releases IL- $6{ }^{17}$ and microparticles ${ }^{18}$ on IL- $1 \beta$ stimulation. We show that collagen IV-expressing vascular endothelial cells in CNV express IL-1RI in vivo (Figure 3). To evaluate a direct effect of IL-1 $\beta$ on vascular sprouting independently of inflammatory recruitment, we submitted aortic rings to $\mathrm{IL}-1 \beta$ in vitro (Figure 3 ). We show that IL-1 $\beta$ significantly induces vascular sprouting of aortic rings after 24 hours of $\mathrm{IL}-1 \beta$ exposure. This difference was maintained for up to 72 hours of $\mathrm{IL}-1 \beta$ incubation. A previous study has shown an inhibitory effect of $\mathrm{IL}-1 \beta$ on vascular sprouting in the aortic ring assay at 10 days. ${ }^{29}$ In our study, aortic rings became unviable after 7 days in culture, and we could therefore not corroborate or contradict these findings. IL-1 $\beta$ has been suggested to induce angiogenesis via a sustained VEGF induction in fibroblasts. ${ }^{30}$ In our in vivo experiments we did not detect a sustained VEGF induction after the IL-1 $\beta$ induction in laser-injured eyes. Furthermore, vascular sprouting of aortic rings simultaneously incubated with $\mathrm{IL}-1 \beta$ and the soluble VEGFR1 did not differ from rings incubated only with $\mathrm{IL}-1 \beta$, suggesting that the pro-angiogenic effect is independent of VEGF. Previous studies have shown that $\mathrm{IL}-1 \beta$ directly induces $\mathrm{IL}-6^{17}$ and microparticle release from the vascular endothelium ${ }^{31}$ and that $\mathrm{IL}-1 \beta$ inhibitor CK112 and CK116 inhibit human umbilical vein endothelial cell proliferation. ${ }^{16}$ The pro-angiogenic effect of IL-1 $\beta$ we observed in vivo and in vitro might therefore be a direct effect of endothelial cell proliferation.

In AMD, subretinal neovascularization occurs simultaneously with retinal degeneration. To make anti-IL-1 $\beta$ therapy a viable option, the influence of IL-1 $\beta$ on photoreceptors has to be evaluated in vivo. Previous reports have shown that IL-1 $\beta$ develops neurotoxic properties in the brain. ${ }^{5,13,32}$ However, in the retina IL-1 $\beta$ was shown to inhibit ganglion cell death, ${ }^{6}$ and IL-1 $\beta$ substitution saved photoreceptors in light-induced models ${ }^{7}$ and genetic retinal degeneration. ${ }^{8}$ Here, we show that $\mathrm{IL}-1 \beta$ is significantly induced in the light-induced model in albino rats (Figure 4D) and in albino mice (Figure 5B). To test the effect of $\mathrm{IL}-1 \beta$ inhibition on retinal degeneration, we treated the laser-injured C57BL/6 mice and light-exposed rats with IL-1Ra at dosages that were sufficient to significantly inhibit CNV in mice (see Figure 2) and rats. ${ }^{14}$ Interestingly, IL-1Ra at a dose that significantly inhibits CNV does not exacerbate photoreceptor degeneration in vivo (Figure 4).

We have previously shown that a dysfunctional CX3CR1 is associated with AMD. Cx3Cr1 ${ }^{-1-}$ mice develop spontaneous subretinal macrophage accumulation that is associated with photoreceptor degeneration by the age of 18 months. ${ }^{19}$ Similarly, these mice develop exaggerated photoreceptor degeneration in light-induced models. ${ }^{20}$ We analyzed the expression and effect of IL-1 $\beta$ in the $C \times 3 \mathrm{Cr}^{-1-}$ model of AMD. IL-1 $\beta$ significantly increases with age in $C \times 3 \mathrm{Cr}^{-1-}$ animals. This increase coincides with the observed subretinal inflammation in these animals ${ }^{19}$ and might reflect IL-1 $\beta$ produced by subretinal inflammatory cells. In light-induced injury to BALB CX3Cr1 ${ }^{+/+}$and $C \times 3 C r 1^{-1-}$ mice, IL-1 $\beta$ was rapidly induced, similar to the rat and to laser-induced CNV. As shown in the mouse CNV model and rat models (Figure 4), IL-1Ra substitution in control and light-exposed $\mathrm{C} \times 3 \mathrm{Cr}^{-1-}$ mice in dosages sufficient to significantly inhibit CNV had no deleterious effect on photoreceptor survival (Figure 5). Although exogenous IL-1 $\beta$ substitution has been shown to protect photoreceptor degeneration in a light-induced model, ${ }^{7}$ its inhibition does not exacerbate degeneration in wild-type mice (CNV model) or light-exposed rats or in degeneration-prone $\mathrm{C} \times 3 \mathrm{Cr} 1^{-1-}$ mice. The apparent contradiction of IL- $1 \beta$-mediated photoreceptor protection and the absence of an exacerbating effect of IL-1Ra might be explained by different IL-1 $\beta$ concentrations. Although the neuroprotective effect of LaVail et $\mathrm{al}^{7}$ and Whiteley et $\mathrm{al}^{8}$ are found at concentrations of 0.5 to $5 \mu \mathrm{g}$ of IL- $1 \beta$ per eye, the maximum IL-1 $\beta$ concentration we measured with age- and light-induced injury correspond to approximately 50 pg/eye. The endogeneously produced amount of IL-1 $\beta$ might therefore be well below neuroprotective concentrations and therefore have no effect on photoreceptor survival.

In summary, IL-1 $\beta$ is induced by laser- and light-induced injury. We confirm that IL-1Ra substitution efficiently inhibits the development of CNV in the mouse and show that it has no deleterious effect on photoreceptor survival. Taken together, our data suggest that IL-1Ra is a safe alternative for the treatment of neovascular AMD. 


\section{Acknowledgments}

We thank Christopher Brent Murray for critical review of the manuscript and Bernadette Lescure and Nadège Brunel for technical assistance.

\section{References}

1. Dinarello CA: Immunological and inflammatory functions of the interleukin-1 family. Annu Rev Immunol 2009, 27:519-550

2. Isoda K, Sawada S, Ishigami N, Matsuki T, Miyazaki K, Kusuhara M, Iwakura Y, Ohsuzu F: Lack of interleukin-1 receptor antagonist modulates plaque composition in apolipoprotein E-deficient mice. Arterioscler Thromb Vasc Biol 2004, 24:1068-1073

3. BenEzra D, Hemo I, Maftzir G: In vivo angiogenic activity of interleukins. Arch Ophthalmol 1990, 108:573-576

4. Carmi Y, Voronov E, Dotan S, Lahat N, Rahat MA, Fogel M, Huszar M, White MR, Dinarello CA, Apte RN: The role of macrophage-derived $\mathrm{IL}-1$ in induction and maintenance of angiogenesis. J Immunol 2009, 183:4705-4714

5. Yamasaki $Y$, Matsuura $N$, Shozuhara $H$, Onodera $H$, Itoyama $Y$, Kogure K: Interleukin-1 as a pathogenetic mediator of ischemic brain damage in rats. Stroke 1995, 26:676-680; discussion 681

6. Namekata K, Harada C, Guo X, Kikushima K, Kimura A, Fuse N Mitamura Y, Kohyama K, Matsumoto Y, Tanaka K, Harada T: Interleukin-1 attenuates normal tension glaucoma-like retinal degeneration in EAAC1-deficient mice. Neurosci Lett 2009, 465:160-164

7. LaVail MM, Unoki K, Yasumura D, Matthes MT, Yancopoulos GD, Steinberg $\mathrm{RH}$ : Multiple growth factors, cytokines, and neurotrophins rescue photoreceptors from the damaging effects of constant light. Proc Natl Acad Sci U S A 1992, 89:11249-11253

8. Whiteley SJ, Klassen H, Coffey PJ, Young MJ: Photoreceptor rescue after low-dose intravitreal IL-1beta injection in the RCS rat. Exp Eye Res 2001, 73:557-568

9. Friedman DS, O'Colmain BJ, Munoz B, Tomany SC, McCarty C, de Jong PT, Nemesure B, Mitchell P, Kempen J: Prevalence of agerelated macular degeneration in the United States. Arch Ophthalmol 2004, 122:564-572

10. Sarks SH: Ageing and degeneration in the macular region: a clinicopathological study. Br J Ophthalmol 1976, 60:324-341

11. Oh H, Takagi H, Takagi $C$, Suzuma K, Otani A, Ishida K, Matsumura M, Ogura $Y$, Honda $Y$ : The potential angiogenic role of macrophages in the formation of choroidal neovascular membranes. Invest Ophthalmol Vis Sci 1999, 40:1891-1898

12. Pascual V, Allantaz F, Arce E, Punaro M, Banchereau J: Role of interleukin-1 (IL-1) in the pathogenesis of systemic onset juvenile idiopathic arthritis and clinical response to IL-1 blockade. J Exp Med 2005, 201:1479-1486

13. Banwell V, Sena ES, Macleod MR: Systematic review and stratified meta-analysis of the efficacy of interleukin-1 receptor antagonist in animal models of stroke. J Stroke Cerebrovasc Dis 2009, 18:269-276

14. Olson JL, Courtney RJ, Rouhani B, Mandava N, Dinarello CA: Intravitreal anakinra inhibits choroidal neovascular membrane growth in a rat model. Ocul Immunol Inflamm 2009, 17:195-200

15. Checchin D, Sennlaub F, Levavasseur E, Leduc M, Chemtob S: Potential role of microglia in retinal blood vessel formation. Invest Ophthalmol Vis Sci 2006, 47:3595-3602

16. Zou Y, Xu X, Chiou GC: Effect of interleukin-1 blockers, CK112, and CK116 on rat experimental choroidal neovascularization in vivo and endothelial cell cultures in vitro. J Ocul Pharmacol Ther 2006, 22:19-25

17. Boraschi D, Rambaldi A, Sica A, Ghiara P, Colotta F, Wang JM, de Rossi M, Zoia C, Remuzzi G, Bussolino F, et al: Endothelial cells express the interleukin-1 receptor type I. Blood 1991, 78:1262-1267

18. Leroyer AS, Rautou PE, Silvestre JS, Castier Y, Leseche G, Devue C, Duriez M, Brandes RP, Lutgens E, Tedgui A, Boulanger CM: CD40 ligand + microparticles from human atherosclerotic plaques stimulate endothelial proliferation and angiogenesis a potential mechanism for intraplaque neovascularization. J Am Coll Cardiol 2008, 52:13021311

19. Combadiere C, Feumi C, Raoul W, Keller N, Rodero M, Pezard A, Lavalette S, Houssier M, Jonet L, Picard E, Debre P, Sirinyan M, Deterre P, Ferroukhi T, Cohen SY, Chauvaud D, Jeanny JC, Chemtob S, Behar-Cohen F, Sennlaub F: CX3CR1-dependent subretinal microglia cell accumulation is associated with cardinal features of agerelated macular degeneration. J Clin Invest 2007, 117:2920-2928

20. Raoul W, Keller N, Rodero M, Behar-Cohen F, Sennlaub F, Combadiere C: Role of the chemokine receptor CX3CR1 in the mobilization of phagocytic retinal microglial cells. J Neuroimmunol 2008, 198: 56-61

21. Daley JM, Thomay AA, Connolly MD, Reichner JS, Albina JE: Use of Ly6G-specific monoclonal antibody to deplete neutrophils in mice. J Leukoc Biol 2008, 83:64-70

22. Imai Y, Ibata I, Ito D, Ohsawa K, Kohsaka S: A novel gene iba1 in the major histocompatibility complex class III region encoding an EF hand protein expressed in a monocytic lineage. Biochem Biophys Res Commun 1996, 224:855-862

23. Tsutsumi-Miyahara C, Sonoda KH, Egashira K, Ishibashi M, Qiao H, Oshima T, Murata T, Miyazaki M, Charo IF, Hamano S, Ishibashi T: The relative contributions of each subset of ocular infiltrated cells in experimental choroidal neovascularization. $\mathrm{Br} \mathrm{J}$ Ophthalmol 2004 , 88:1217-1222

24. Malyak M, Smith MF Jr, Abel AA, Arend WP: Peripheral blood neutrophil production of interleukin-1 receptor antagonist and interleukin-1 beta. J Clin Immunol 1994, 14:20-30

25. Matsumoto $H$, Kumon $Y$, Watanabe $H$, Ohnishi $T$, Shudou M, li C, Takahashi H, Imai Y, Tanaka J: Antibodies to CD11b, CD68, and lectin label neutrophils rather than microglia in traumatic and ischemic brain lesions. J Neurosci Res 2007, 85:994-1009

26. Espinosa-Heidmann DG, Suner IJ, Hernandez EP, Monroy D, Csaky KG, Cousins SW: Macrophage depletion diminishes lesion size and severity in experimental choroidal neovascularization. Invest Ophthalmol Vis Sci 2003, 44:3586-3592

27. Sakurai E, Anand A, Ambati BK, van Rooijen N, Ambati J: Macrophage depletion inhibits experimental choroidal neovascularization. Invest Ophthalmol Vis Sci 2003, 44:3578-3585

28. Zhou J, Pham L, Zhang N, He S, Gamulescu MA, Spee C, Ryan SJ, Hinton DR: Neutrophils promote experimental choroidal neovascularization. Mol Vis 2005, 11:414-424

29. Mountain DJ, Singh M, Singh K: Interleukin-1beta-mediated inhibition of the processes of angiogenesis in cardiac microvascular endothelial cells. Life Sci 2008, 82:1224-1230

30. Kvanta A: Expression and regulation of vascular endothelial growth factor in choroidal fibroblasts. Curr Eye Res 1995, 14:1015-1020

31. Leroyer AS, Ebrahimian TG, Cochain C, Recalde A, Blanc-Brude O, Mees B, Vilar J, Tedgui A, Levy BI, Chimini G, Boulanger CM, Silvestre JS: Microparticles from ischemic muscle promotes postnatal vasculogenesis. Circulation 2009, 119:2808-2817

32. Cardona AE, Pioro EP, Sasse ME, Kostenko V, Cardona SM, Dijkstra IM, Huang D, Kidd G, Dombrowski S, Dutta R, Lee JC, Cook DN, Jung S, Lira SA, Littman DR, Ransohoff RM: Control of microglial neurotoxicity by the fractalkine receptor. Nat Neurosci 2006, 9:917-924 